\title{
De küme mollfüñche a "civilizados a medias": liderazgos étnicos e intelectuales mapuche en la Araucanía fronteriza (1883-1930)
}

\author{
José Ancan Jara \\ CECLA, Universidad de Chile, Santiago, Chile. \\ Email: pepepindako@gmail.com
}

\begin{abstract}
Resumen: ${ }^{1}$ Pese a la incorporación de su territorio a los Estados chileno y argentino, los mapuche supieron mantener y/o resignificar expresiones socioculturales propias y originales. A contar de 1910, los liderazgos tradicionales se proyectaron en las organizaciones étnicas que, representando un nuevo dispositivo de poder, fueron conformadas por preceptores normalistas que habían accedido a la educación formal chilena a través de un ardid diseñado por jefes militares chilenos. La instrucción proporcionada permitió a estos sujetos legitimarse tanto al interior de la sociedad mapuche, como frente a distintos agentes del Estado. Algunos de estos líderes, como Manuel Mañkelef, produjeron e hicieron circular textos en formato bilingüe, lo que les permitió establecer contactos y gozar de ciertos privilegios, pero también generar conflictos con miembros de la academia chilena, constituyéndose así en un preludio de los entresijos y desafíos muy actuales de la denominada "intelectualidad" mapuche.
\end{abstract}

Palabras clave: conocimiento; poder; tradición mapuche; escritura; relaciones interétnicas.

\section{From küme mollfüñche to "half way civilized": ethnic leadership and Mapuche intellectuals in the borderland Araucanía (1883-1930)}

Abstract: Despite of the forced incorporation of their territory to the Chilean and Argentinean states, the Mapuche people went around and managed to maintain or resignificate sociocultural elements of their own and original. Since 1910 , the customary leaderships reoriented themselves towards ethnical organizations that, representing a new mode of power, were occupied by educated scholars raised in formal Chilean schools, by ways of a trick designed by Chilean military chiefs. The educational background of those leaders allowed them to gain legitimacy both within their own Mapuche society as well as within different State representatives. Some of these leaders, such as Manuel Mañkelef, produced and published bilingual documents, both in spanish and mapudungun, which allowed them to establish contacts and enjoy certain privileges, as well as to generate conflicts with Chilean scholars, becoming thus into a prelude to the current challenges of what is known as the Mapuche "intellectuality". relations.

Key words: knowledge; power; Mapuche tradition; writing; interethnic 


\section{De küme mollfüñche para "meio civilizados": lideranças étnicas intelectuais Mapuche na Araucanía fronteiriça (1883-1930)}

Resumo: Apesar da incorporação de seu território para os Estados de Chile e Argentina, os Mapuche foram capazes de manter e/ou significar expressões culturais próprias e originais. Começando em 1910, os líderes tradicionais constituíram-se nas organizações étnicas que, representando um novo dispositivo de poder, foram moldados por preceptores normalistas que tinham acessado à educação formal chileno através de um ardil concebido por líderes militares chilenos. A instrução dada possibilitou que eles se legitimassem tanto no seio da sociedade Mapuche, como perante diversos agentes do Estado. Alguns destes líderes, como Manuel Mañkelef produziram e fizeram textos em formato bilíngue, o que lhes permitiu estabelecer contatos e desfrutar de certos privilégios, mas também gerar conflitos com os membros da Academia Chilena, tornando-se assim num prelúdio das contrariedades e desafios muito atuais da chamada "intelligentsia” Mapuche. interétnicas.

Palavras-chave: conhecimento; poder; tradição Mapuche; escrita; relações

\section{Introducción}

La incorporación forzada del territorio mapuche a los Estados de Chile y Argentina, a fines del siglo XIX, generó importantes desestructuraciones en el interior de la sociedad mapuche. Junto con la desaparición de muchas formas socioculturales autónomas, otras tantas mutaron y/o se resignificaron, apareciendo nuevos actores sociales dentro del espacio interétnico. En Chile, las organizaciones mapuche reemplazaron en la interlocución con el Estado a las estructuras de poder tradicional, a partir de 1910 tuvieron un rol trascendental, así como parte de los liderazgos que inicialmente condujeron dichos referentes. Aludimos al grupo de profesores normalistas mapuche, que habían sido formados por la Escuela Normal de Preceptores, creada en 1842 por el intelectual argentino Domingo Faustino Sarmiento, autor del "Facundo" y adalid de la antinomia civilización / barbarie. Determinante fórmula aquella, en que -obviamente- los indígenas ocupaban el lugar de los "salvajes” que debían ser irremediablemente integrados, cuando no absorbidos intelectual e incluso físicamente, por la autoproclamada superioridad de la civilización representada por gente como Sarmiento y su institución.

Había ya a lo menos una generación de preceptores normalistas mapuche titulados al momento de procederse a la ocupación de la Araucanía. Dicho sector había accedido a la educación formal a través de una estratagema concebida por quien planificó y estuvo al mando de dicha campaña, Cornelio Saavedra, y continuada por José Manuel Pinto. El ardid consistía derechamente en el secuestro de un hijo por cada longko ${ }^{2}$ importante, con el fin de trasladarlos a Santiago y educarlos ahí. Este "apadrinamiento educativo” era obviamente una operación encubierta, como una especie de acuerdo de paz. La estrategia militar imaginaba que, mediante esa educa- 
ción, estos jóvenes, una vez titulados y retornados a sus tierras, integrarían "por chorreo" a sus hermanos de "raza" mediante el ejercicio de su profesión.

La historia posterior demostró sin embargo la falacia del artificio. La falla original estuvo en que, para los agentes de poder chileno -político, académico y social-, pese a la educación adquirida, los preceptores y en general cualquier sujeto mapuche, a lo sumo podía sólo aspirar a la categoría de "civilizados a medias", condición que implícitamente incluía la convicción ideológica de que el resto "salvaje” era irremisible. Más allá de lo auténticamente primitiva de tal fórmula, lo cierto es que estos profesionales mapuche, no sólo no se asimilaron en las aulas chilenas, sino que a poco andar se transformaron en líderes de los dispositivos de poder inaugurados en el nuevo contexto. La educación formal adquirida, unida al origen social del que provenían estos líderes -hijos de longko importantes- les posibilitó adquirir, seguramente sin proponérselo, una posición estratégica respecto de ambas sociedades. De esta forma, pudieron legitimarse ante sus iguales, mediante las redes de prestigio acumuladas dentro del complejo espacio de relaciones interétnicas de principios del siglo XX, tejidas en un contexto particularmente difícil para la sociedad mapuche.

Los normalistas mapuche fueron entonces capaces de utilizar lo mejor de las armas adquiridas en la educación formal decimonónica, principalmente la escritura en registro bilingüe, pudiendo aplicarlas en su labor dirigencial, donde la demanda por educación formal precisamente fue una de las bases de las primeras reivindicaciones sociopolíticas. Este repertorio argumental fue gestado en un ambiente particularmente adverso. Pese a esto, aquellos liderazgos no sólo posibilitaron establecer un dique de contención ante el masivo despojo territorial, sino que posicionaron a parte de esa dirigencia originaria en condiciones de interrelacionar, con mayor o menor audiencia, con diversos agentes estatales y sociales chilenos.

Más allá de aquello -y es lo que puntualmente nos interesa aquí-, algunos de estos líderes se dieron el tiempo para producir y hacer circular conocimiento en formato escritural. Para lograr esto, se valieron de los contactos y agenciamientos generados en el ambiente académico chileno "araucanista". Este pequeño sector de intelectuales paradojalmente estaba convencido, como en el caso de Guevara (1908, 1912), Matus (1915, 1920) o Lenz (1895-1897), entre otros, que esa sociedad y cultura mapuche tan ávidamente investigada por ellos, estaba irremisiblemente condenada a desaparecer a poco andar, absorbida por aquella civilización que ellos aspiraban encarnar. Es sintomático de las creencias de estos autores acerca de la sociedad mapuche, que una de las obras más importantes de Guevara, en la que quizás más y mejor se aprecia el trabajo de sus ayudantes nativos, se titulase Las últimas familias y costumbres araucanas (Guevara 1912) .

En este ensayo, intentamos establecer algunos puntos cruciales desencadenados dentro de esta escena. En especial las particulares estra- 
tegias y de generación de discurso público desarrolladas por las dirigencias de las primeras organizaciones mapuche de principios del siglo XX, liderazgos que compartían el rasgo de ser profesores formados para la asimilación. Ello posibilitó, no sólo la subversión desde dentro de una de las claves de un mecanismo político, sino que este hecho permitió a su vez la aparición de la figura del intelectual mapuche contemporáneo. Se establece la reflexión a partir de ciertos hechos y personajes considerados como claves: esto es, los preceptores normalistas mapuche; el surgimiento de las organizaciones étnicas y el rol de personajes emblemáticos, como Manuel Antonio Neculman y Manuel Mañkelef ${ }^{4}$. De manera particular, nos interesa la relación de este último con Tomás Guevara e indirectamente con Rodolfo Lenz. Nos importa indagar en primer lugar en algunas circunstancias específicas del surgimiento de la primera generación de “intelectuales mapuche”, así como el contexto histórico mapuche y chileno, de fines del siglo XIX y principios de XX. Así también, buscamos establecer aquí algunas líneas de reflexión que posibiliten analizar este contexto histórico. Por último, sugerimos a modo de conclusión un ejercicio de extrapolación entre la situación de los preceptores normalistas mapuche de comienzos del siglo XX, y la actual generación de denominados “intelectuales mapuche” (Munizaga 1960; Zapata 2005, 2007, 2008; Le Bonniec 2011, entre otros) y sus coetáneos vínculos con el conocimiento y opciones políticas autónomas, y los nexos establecidos - personal o colectivamente-con la academia chilena de este tiempo.

\section{“Civilizados a medias" que dirigen escuelas}

A principios de enero de 1883, llega a la naciente aldea de Temuko ${ }^{5}$ Pedro Nolasco Préndez Murúa. Poeta, posterior diputado suplente por Constitución (1888-1891), a la sazón cronista que funge de Secretario de la Expedición a Villarrica, cuya misión era la de seguir y documentar la última campaña militar de la “Pacificación”. Comandada por el coronel Gregorio Urrutia, a fines del 1882 esta caravana había emprendido la simbólica tarea de sellar la ocupación total del territorio mapuche en un lugar y evento definitorios. En efecto, aquella marcha se dio al objetivo de refundar el poblado de Villarrica con el mismo nombre y en el lugar exacto donde estaban los vestigios de la primera fundación, hecha en abril de 1552 por soldados españoles al mando de Gerónimo de Alderete, lugarteniente de Pedro de Valdivia. La expedición refundadora de Urrutia y Préndez había de avanzar desde Temuko hacia el sur, abriéndose paso entre el espeso bosque, y luego de fundar en los últimos días de 1882 el fuerte de Freire, para enfilar hacia el oriente remontando el río Toltén. La expedición culmina finalmente su avance en las ruinas de la primera Villarrica, el día 1 de enero, en lo que eran las tierras del longko Epulef, a orillas del lago conocido por los habitantes originarios como Mallolafken.

Préndez, que marcha a la saga de la caravana, va dejando constancia escrita de su excursión por esa Araucanía recién chilenizada. En su periplo abarca un amplio recorrido que va desde Angol a Valdivia, 
pasando por Villarrica. En esta crónica, aparte de las tareas políticoadministrativas, deja además constancia de las dotes literarias de las que hacía gala en el grupo constituido en la "sala de redacción” del diario La Época de Santiago. En tierras araucanas, el cronista se sentirá arrobado, cual ecologista profundo de nuestros tiempos por la majestuosidad de los bosques vírgenes. Naturaleza indómita de la que Préndez, como casi todos los intelectuales de su tiempo, estaba consciente de lo poco que le quedaba incólume, antes que fuera sometida como las personas que la habitaban, por el avance irrefrenable de la civilización:

[...] al mirar tan grueso tronco, la vista cree que contempla las columnas de algún suntuoso templo o de alguna lujosa sala, demasiado grande y elevada para servir de mansión a los hombres, pero digna de presenciar las danzas de una raza de titanes o de semi-dioses, al compás de la música monótona que el viento toca oculto en las más altas ramas y que no alcanza a hacerse sentir en la superficie siempre humedecida por las fuentes que sirven de espejo al follaje [... contemplando este conjunto desde el sitio que ocupábamos y analizando sus detalles, se nos figuró que presenciábamos el sacrificio que la naturaleza ofrecía en ese instante a su Creador. El árbol cubierto de hojas era el sacerdote; el altar, la ladera; los cirios, los troncos blancos; el humo, el incienso que se quemaba a la divinidad; y los cantos de las aves, la orquesta sublime llamada a amenizar esa ceremonia (Préndez 1884: 27-31).

Es en esa naturaleza desbordada e inabarcable que en la profunda oscuridad de una noche, en medio del bosque entre Lautaro y Temuko, en un gesto que encierra rasgos alegóricos, el cronista-poeta hace anotaciones y lee fragmentos de La Araucana bajo las luces de las luciérnagas veraniegas. Mientras, imagina símiles de ritos vegetales de sometimiento al progreso, a los que inevitablemente deben adherir los indígenas de carne y hueso con los que se va encontrando por el camino. Para Préndez, allí no hay soluciones intermedias. O estos se someten a la tala de los bosques que abren la senda para el trazado del ferrocarril, o cuando mucho, podrán aspirar a ser asistidos por coletazos de ese progreso.

Llegado a Temuko, Préndez conoce a un individuo que le hace enarbolar la suma de sus ideas -que son las mismas de la élite de su tiempo- respecto a la sociedad indígena recién incorporada. Nociones que -no está demás decirlo- en más de un sentido siguen vigentes en un sector de la sociedad dominante. Préndez entonces describe así al flamante preceptor de la primera escuela pública fundada en Temuko, el profesor mapuche de Boroa, Manuel Antonio Neculman:

El preceptor es un apreciable joven hijo del cacique Neculman y ha sido educado en la Escuela Normal de Santiago, en donde permaneció varios años [...]. Don Manuel Antonio Neculman [...] nos pareció un mozo muy cumplido y atento; parece que ha apren- 
dido muy bien cuanto ha estudiado, sobre todo la historia de Chile. Su educación se resiente, como es natural, de falta de conocimiento del mundo y de la sociedad española en que vive. Su corazón es sano y puro, ofreciendo en su conjunto un contraste notable su sencillez de cristiano y su candor de indígena, sin que estrictamente hablando, sea hoy lo uno u lo otro (Préndez 1884: 33).

“Ni lo uno ni lo otro”. Es la imagen del nativo que por más que lo intente, tan sólo podrá aspirar a ser mitad civilizado, lo cual inaugura en el discurso de nuestro cronista la estrategia chilena hegemónica con respecto a la sociedad mapuche. Estrategia fracasada ya en su gestación, no sólo por sus contradicciones, sino que en su mismo enunciado. Una relación construida a sangre y fuego en nombre de la civilización y el progreso avasallantes, que según se pensaba por entonces, a corto andar inevitablemente acabaría con la cultura aborigen, absorbida -vía su asimilación- a la sociedad mayoritaria. Lo mismo que la solución territorial implementada por el Estado para atender a la población indígena sobreviviente a la "Pacificación”: el arreduccionamiento, a la larga, derivará en una solución que no operó completamente; la imagen ideológica del indígena “civilizado a medias”, no obstante la validación académica obtenida en la institucionalidad wingka, guardará siempre un resto salvaje que le condenará ante sus dominadores.

De esta forma, para Préndez, no será aceptable que el encargado de inaugurar y dirigir la institución más concluyente y definitoria del proyecto civilizador estatal -la educación primaria que construirá ciudadanos- no sea un ciudadano auténticamente chileno, sino que un indígena reconvertido en profesor normalista. Es que Neculman está ejerciendo allí su doble condición: ser parte de una de las más refinadas estrategias de integración ideadas por los mandos militares, pero a la vez sin dejar de ser lo que siempre será, un foroweche ${ }^{6}$.

Manuel Antonio Neculman y la mayoría de los normalistas mapuche pertenecían a un sector preciso dentro de la compleja estructura de poder de la sociedad indígena de fines del siglo XIX. Esto es, formaban parte de familias de longko. Neculman, oriundo de Boroa, era hijo de uno de los principales y más poderosos jefes mapuche autónomos del siglo XIX, instigador del último malon, la insurrección armada mapuche de noviembre de 1881, cuyo objetivo final era precisamente arrasar con el emergente fortín que se había emplazado junto al río Cautín.

El plan de educar civilizando a jóvenes mapuche para que a su vez estos civilizaran a otros, no era fruto del azar. Los mandos militares, como el mismo Cornelio Saavedra, de quien se dice que llegó a apadrinar por lo menos a 20 jóvenes, familiares directos de jefaturas tradicionales, conocían de cerca la trama de las complejas y estratificadas redes de poder mapuche independiente. Por lo mismo, trataron siempre de incidir directa o indirectamente en ellas, ya sea mediante amenazas encubiertas de pactos puntuales; pago de favores; asignaciones de bienes; cargos y dinero. Dice el testimo- 
nio de uno de los normalistas mapuche y posterior ayudante de campo, narrador y escribiente bilingüe de Tomás Guevara, el nagche -habitante de las tierras bajas de Malleco-Lorenzo Koliman?:

El general don Cornelio Saavedra me pidió a mi padre para educarme. Me mandó con un teniente García, de caballería, a Santiago. Entré en la Escuela Normal de Preceptores. Estuve tres años; el mismo general me sirvió de apoderado (Guevara \& Mañkelef 2002 [1912]:45).

No se trataba de educar a estos jóvenes en algún oficio manual, como lo hicieran posteriormente las misiones de evangelización cristianas, especialmente la anglicana. Lo que se proponía era formar preceptores normalistas que fueran conocedores y lectoescritores en ambas culturas y por sobre todo, eventuales futuros funcionarios de las recién creadas estructuras administrativas dentro del territorio anexado. De hecho, si no en la labor docente, muchos de estos sujetos -como el mismo Kolimañ- se desempeñaron como oficiales traductores de los Juzgados de Indios, Comisión Radicadora de Indígenas o la administración local.

La Escuela Normal de Preceptores, la primera en su tipo en América Latina, había sido creada y dirigida desde sus comienzos (1842) por Domingo Faustino Sarmiento. El intelectual argentino, fue una verdadera inspiración ideológica de las campañas de ocupación y colonización de los territorios en poder de las sociedades originarias, en ambos lados de Los Andes:

El mal que aqueja a la República Argentina es la extensión: el desierto la rodea por todas partes y se le insinúa en las entrañas; la soledad, el despoblado, sin una habitación humana [...] al sur y al norte acéchanla los salvajes, que aguardan las noches de luna para caer, cual enjambre de hienas, sobre los ganados que pacen en los campos y sobre las indefensas poblaciones (Sarmiento 1845: 20).

Según el programa de estudios elaborado por el propio Sarmiento, en la Escuela Normal de Preceptores se establecería un régimen en el cual la disciplina y el orden en todos los aspectos eran lo primordial. Sus contenidos resultan ser una clara muestra de los fundamentos de la ideología con que el Estado nacional chileno aspiraba a formar a su gente. Se enseñaba allí manejo a la perfección de la lectoescritura, dogma y moral religiosa, aritmética comercial, gramática, historia y geografía de Chile, además de gimnasia. Se trataba entonces de una formación integral, imbuida en el espíritu positivista decimonónico, donde lo esencial era superar el estado de barbarie originaria: "[Se formarán] maestros idóneos i de conocida moralidad, i mediante métodos fáciles, claros i uniformes, que ahorrando tiempo i dificultades, la hagan estensiva a todas las clases de la sociedad" (Sarmiento, citado por Núñez Prieto 2010: 34). 


\section{“Civilizados a medias"}

De esta suerte, en enero de 1883, confluyen en la escuelita-fortín de Temuko, personajes y sucesos cargados de simbolismos: el preceptor mapuche "medio civilizado"; el cronista con ínfulas de poeta; los soldados obreros que custodian el fortín; los alumnos en su mayoría chilenos y unos pocos mapuche de la escuelita de Neculman, entre otros. En tal emplazamiento, se proyectan el desencuentro, la negación y los prejuicios que nos ilustran acerca de la historia interétnica contemporánea en la Araucanía. Con lógicas contrapuestas, eran, de esta forma, dispares los ingredientes y las intenciones de todos quienes participan allí. Por una parte, la educación normalista inaugurada por el autor del Facundo; la ocupación y el arreduccionamiento o segmentación discursiva de la condición indígena. Por otra parte, visto desde la otra mitad de la ecuación, en la apuesta del resto "salvaje", se halla el surgimiento de una generación de jóvenes mapuche que, vía pactos obligados con los militares, había accedido en el siglo XIX a una educación privilegiada para la época; y por otro lado, la legitimación de las estructuras de poder tradicionales, que sin pretenderlo la estrategia chilena, se reforzarán en el nuevo contexto del siglo XX, a través de los liderazgos organizacionales.

Así, Préndez resuelve la contradicción que se le presenta al encontrarse con un indígena a cargo de la escuela -la primera y única escuela de Temuko- ejecutando el acto supremo de la escritura descriptiva, es decir aplicando una mirada analítica a partir de una posición de superioridad autoasumida. En ese gesto, Neculman es reducido -diseccionado socioculturalmente- a su mitad aparentemente neutra, no es "ni lo uno ni lo otro", pero aun así, lo que en realidad pesa es su condición "salvaje”, la que no había alcanzado a ser redimida por la educación normalista y su proyecto de docilidad ciudadana. Eso es lo que en el fondo de su chilenidad piensa del preceptor el poeta. Por eso resalta de él los atributos de la domesticación, que son también hasta hoy día los de todo "indio permitido”, “cumplido”, “atento”, “corazón sano y puro”, “candor de indígena”, etc.

Con todo, para Préndez no basta que el preceptor "aparentemente" haya olvidado su lengua materna. Es que no se ha civilizado completamente, pues guarda en su interior la mitad salvaje que lo hace incompleto y por tanto peligroso. He ahí el fracaso de la metáfora integradora. Los indígenas nunca se civilizan completamente, pues su mitad civilizada, a lo sumo será tan sólo un aporte a los estudios etnológicos y folklóricos.

La condición de "civilizado a medias" inaugura un discurso y unas prácticas estatales que en su momento -y hasta nuestros días- se han nutrido de un buen argumento de mediación interétnica, elaborada desde la condición y el poder estatal, argumento erigido como una fórmula que trasciende a la sociedad. Desde la ideología estatal, o en un correlato de ésta como sería la investigación etnográfica clásica, los "civilizados a medias" se habrían constituido en prototipos de informantes o ayudantes de terre- 
no, traductores de literatura indígena o funcionarios y operadores indigenistas. Es lo que Préndez pensaba de Neculman en 1883. Era sólo un buen funcionario público.

Aparente metáfora de un destino ineludible, visto desde la mirada del poder, esta suerte de profecía inaugural de las intrincadas relaciones mapuche-chilena contemporáneas, la condición Neculmaniana a su vez derivó en categoría antropológica -“Araucano letrado” o evolué, dirá Munizaga (1960) a comienzos de los 1960. Pero, la realidad es muchísimo más compleja que los enunciados discursivos.

Exactamente 27 años más tarde de aquel encuentro, la asimilación del preceptor quedará por lo menos en entredicho. Precisamente, en julio de 1910, dos meses antes del hito centenario chileno, aparece un nuevo actor dentro del escenario sociopolítico fronterizo: la Sociedad Caupolicán Defensora de la Araucanía (SCDA), primera organización social mapuche del siglo XX, que en su primera directiva no sólo es presidida por el mismo Manuel Antonio Neculman de la escuela-fortín, sino que incorpora como presidente honorario a Tomás Guevara, y como uno de sus directores al reverendo anglicano Charles Sadleir (Foerster \& Montecino 1988).

La SCDA, junto a las otras organizaciones mapuche surgidas años posteriores, no sólo inaugura el discurso público mapuche contemporáneo y su relación con el Estado chileno, sino que -sin proponérselo- incorpora una interesante y persistente solución de continuidad entre la tradición mapuche independiente, personificada en la figura de las jefaturas tradicionales de los longko y las nuevas formas de detentar el poder en la sociedad mapuche. Este proceso es encabezado precisamente por aquellos a los que la historia oficial había condenado a esa especie de interdicto eterno: "civilizados a medias”, como Neculman, Mañkelef, Huenchullan, Coñuepan, Aburto Panguilef y por extensión, la mayoría de los dirigentes sociales mapuche contemporáneos.

\section{Los “privilegios” del origen en la sociedad mapuche tradicional}

¿Qué mecanismos internos de la sociedad mapuche posibilitaron que se diera tan expeditamente ese traspaso de roles? Una repuesta posible la encontramos en los citados pactos obligados entre los jefes militares con ciertas autoridades mapuche. La lógica era simple: chilenizando a hijos de longko, se apuntaba a su rápida integración y que, una vez regresados a sus tierras, operarían como propagadores entre los suyos, de su propia asimilación. La captura de jóvenes era selectiva, pues no iba dirigida así al conjunto de la sociedad mapuche. Por ejemplo, Manuel Antonio Neculman pertenecía a uno de los trokiñche principales -familias principales de un territorio- de la zona de Boroa / Forowe, cuya jurisdicción o wichan mapu autónomo ocupaba una buena parte del actual territorio de la provincia de Cautín, al sur oeste de Temuko. 
No era en este sentido una medida de promoción social, aunque si explícitamente política. Los jefes del ejército chileno apelan a tomar como rehenes de un pacto de no agresión a los hijos de ciertos jefes mapuche, pues saben que ellos son quienes detentan y ejercen el poder, tienen mando efectivo en grandes extensiones territoriales y que este poder en gran medida es hereditario, es decir, se transmite preferentemente entre los descendientes de ciertas familias ${ }^{8}$. Así describe -hipérbole incluida- la estructura de poder tradicional el propio Mañkelef:

El título de cacique se adquiría entre los araucanos por herencia y por autoridad propia, es decir, por derecho y de hecho. El cacicazgo por herencia era el más común. La antigüedad de una familia y su pasado conocido en la guerra y en la posesión de bienes de fortuna, constituían la nobleza araucana. Los indígenas tenían un marcado apego y respeto a esta nobleza. Para mantener la preponderancia de una familia se necesitaba en primer lugar una parentela numerosa. Con ella podían formarse cuerpos de guerreros más o menos fuertes para el ataque o la defensa. La riqueza de objetos y animales venía como consecuencia, pues la del terreno, sobrante en ese tiempo, no se tomaba en cuenta (Guevara \& Mañkelef 2002 [1912]: 133-134).

En efecto, es en la figura de Manuel Mañkelef González donde tal vez se condensen con mayor nitidez todos los elementos y las complejidades enunciadas. Es hijo de longko, que conoció como primer aprendizaje los contenidos de la educación mapuche tradicional, que adquirió de parte de su ayin kuku, su querida abuela paterna, que lo "cuidó como una reliquia de sus esperanzas” (Manquilef 1911: 5). Ella, sin embargo, al igual que su madre, son mujeres blancas que han sido cautivadas muy jóvenes y luego mapuchizadas, siguiendo una antigua costumbre patriarcal que buscaba también legitimación social interna. El mismo Mañkelef, al referir la historia familiar, reafirma:

Mañkelef [el abuelo de Manuel] tuvo cinco mujeres: Lina, Francisca, Luisa, Llewfü [hilo torcido] y María. Esta última contaba con la predilección de su marido, por ser la menor y cautiva de origen español. Solamente en María procreó los siguientes hijos: Kurüang, Millapü, Wilkañ, Kurümañ y Trekamañ [padre de Manuel], nombres indígenas que la madre cambió por los españoles Manuel, José, Pedro, Antonio y Fermín (Mañkelef, en Guevara \& Mañkelef 2002: 132-133).

Manuel Mañkelef accedió a los diferentes niveles de educación formal chilena de su tiempo (elemental, superior, liceana, y normalista), ya no directamente mediante el pacto político con los militares que caracterizó la formación de los primeros normalistas, sino que como parte del primer contingente de niños mapuche que se incorpora al sistema escolar de principios del siglo XX. Ingresa entonces a la escuela primaria o elemental de Manuel Antonio Neculman, terminado su formación secundaria en el Liceo de Hombres de Temuko, al que ingresa en el año 1900, regresando a sus aulas en 1907, convertido en preceptor normalista. Su primera asignación 
docente allí semeja ser el más fino retrato del proyecto de Sarmiento: profesor de gimnasia y caligrafía, o sea, el disciplinamiento del cuerpo y de la escritura.

En este establecimiento, tanto en su época de alumno como en la de docente, entabla una particular y compleja relación de colaboración, como informante, traductor y redactor en los diferentes trabajos de investigación sobre la cultura mapuche, emprendidos por el profesor de castellano, rector del Liceo, e investigador de la cultura mapuche, Tomás Guevara Silva.

Es precisamente en el despliegue de esta relación, en principio de colaboración pasiva alumno/profesor, la que fue derivando más tarde a la competencia y ruptura en el campo intelectual, donde se manifiesta en toda su crudeza un conflicto de autorías y fines frente a la construcción del conocimiento y la investigación sociocultural originaria. Guevara investigaba y recopilaba tradiciones y saberes mapuche, porque estaba convencido que esas formas culturales tenían los días contados ya que serían absorbidos por las fuerzas irrefrenables e inevitables de la "civilización”. Ella se impondría, ya fuera por la fuerza de la razón o la de las armas, tal cual lo planteara Sarmiento y lo divulgara en el espacio público la prensa del período:

No necesitamos una bula para anexar a la República lo que pertenece a su territorio; ni jamás se habrá presentado una conquista de la civilización sobre los salvajes, que vaya aparejada de mayores requisitos por lo que toca al derecho, a la conveniencia y a la humanidad ${ }^{9}$.

Por eso, constatada la conquista por las armas y ante la inminencia de la inevitable decadencia de las gentes y las formas culturales aborígenes, para Guevara se instala, como una especie de deber cívico, la cruzada recopiladora e inscriptora de taxonomías étnico-culturales. Para esto, sirve por tanto rescatar la mitad anclada en la porción "bárbara” de los indígenas formados por él en las aulas del Liceo de Hombres de Temuko. El ser "ni lo uno ni lo otro" se redime así en el trabajo silente de la compilación etnográfica. En la "advertencia” de una de sus obras más importantes, dice Guevara (1912: 4):

Ha recogido directamente el autor algunas de estas informaciones y otras, asociado de don Manuel Mañkelef [...]. Todas las ha arreglado, además, el señor Mañkelef a un lenguaje legible y correcto del idioma araucano. Por ello deja constancia el autor de su agradecimiento, que hace extensivo a los informantes que con tan buena voluntad lo han secundado en su trabajo.

La aparición del nombre de Mañkelef en el espacio público escritural de su propia cultura se desencadena a contar de la relación personal que éste establece con Rodolfo Lenz ${ }^{10}$. La doble relación de trabajo establecida por Mañkelef, primero con Guevara y luego con Lenz (colaborador y eventual confidente), se establece como paradigma de la apropiación de la escritura y sobre todo la autoría de parte del indígena letrado. El núcleo de las 
relaciones de poder establecidas por Mañkelef con Tomás Guevara, quien nunca modificó sus opiniones de fondo acerca de los sujetos mapuche ${ }^{11}$, establece entonces de hecho la ruptura con el modelo civilizatorio normalista inaugurado por Sarmiento.

Efectivamente, es en la figura de los dirigentes de la primera generación de la SCDA, formados para ser agentes colonizadores mediante su labor pedagógica, donde se establece una suerte de subversión discursiva al modelo normalista, al adoptar esa dirigencia el argumento de la legitimación encerrado en la fórmula "los mapuche somos los primeros chilenos", tesis que hábilmente resitúa la mitad “salvaje” hacia el mismo origen nacional chileno. Este argumento fue profusamente usado por casi todas las organizaciones mapuche de la primera mitad del siglo XX para presentarse ante los agentes estatales chilenos.

\section{“Cheuntu”: el que se hace gente}

Manuel Mañkelef González también encarna en su propia persona aquella remisión. Él era, aplicando un criterio "racial”, nieto e hijo de mujeres blancas y cautivas. Condición mestiza doble, que desde el lado chileno no lo redime, sino que le refuerza su mitad «bárbara». El cautiverio de mujeres blancas estaba instalado en la imaginería de los miedos nacionales desde muy antiguo, constituyéndose en una de las máximas muestras del atribuido salvajismo originario. Aquella condición mestiza, por el contrario, en el mundo mapuche en el que se formó Mañkelef, es devenida y socialmente reconocida: “designáronme con el apodo de Cheuntu, que quiere decir: el que se vuelve jente” (Manquilef [Mañkelef] 1911: 6).

El oriundo de Pülel (Pelal) puede considerarse en propiedad uno de los principales intelectuales y políticos mapuche contemporáneos. Su producción escritural efectivamente publicada es muy escasa, pues suma tan sólo dos obras (ver bibliografía), que si se compara con los abundantes textos que anunció pero nunca publicó es casi un detalle. Además de la validación intelectual que logró en círculos académicos indigenistas de su tiempo, fue electo diputado por el Partido Liberal Democrático, en 1925. En esta condición se transformó en el autor del primer proyecto de ley que planteaba la división en parcelas individuales de los Títulos de Merced colectivos, consagrados por la Ley de Radicación. Esta iniciativa le valió la ruptura pública con gran parte del movimiento mapuche de su tiempo - de hecho fue expulsado de la SCDA- y su posterior retiro no sólo de la actividad política, sino que presumiblemente también de su labor intelectual ${ }^{12}$.

El trabajo intelectual de Mañkelef demarca una permanente fluctuación en los márgenes de un trabajo plenamente inserto en un contexto colonial. El devaneo entre la actuación individual y su quehacer colectivo como intelectual y dirigente étnico y político circula en torno a lo que algunos autores han denominado “doble conciencia” (Mallon 2010). Allí, por una parte, se expresa un compromiso con un proyecto de reivindicación 
étnico-política que oscila permanentemente por entre los bordes de una práctica independiente y, por otra parte, la búsqueda de legitimación dentro de la academia chilena ${ }^{13}$.

Es en la apropiación política de la escritura bilingüe -el "hechizo de la pluma” como él mismo le llamó- donde mejor se expresa en Mañkelef la emergencia de un particular sentido autonómico del quehacer intelectual. Con el poder de la escritura en sus manos, tal vez haya dado cauce al canal de expresión que se cimienta de una parte en la profusa imaginación poética tradicional mapuche, de la cual su padre era depositario; y por la otra, en sus ideas "modernas" respecto de las relaciones interétnicas y la propiedad de las tierras indígenas.

Rodolfo Lenz no compite con Mañkelef por autorías de recopilaciones en terreno, como sí lo hace con Guevara. El filólogo asume la obra del profesor normalista como un buen producto lingüístico filológico, para lo cual la condición champurria o mestiza de Mañkelef ofrece una excelente perspectiva de análisis: “[...] comparar cómo el mestizo bilingüe espresa los mismos pensamientos en sus dos idiomas patrios, partiendo ya del uno, ya del otro” (Lenz, en Mañkelef 1910: 244).

En esta doble tensión, desde la condición de alumno aventajado hasta el mestizo bilingüe, y en la permanente posibilidad de la fuga transgresora, ejercida precisamente por el mismo poder que proporciona la escritura, es donde se jugó en su tiempo el trabajo intelectual de Mañkelef. La posibilidad de haberse formado como investigador siendo parte de un proyecto de recopilación y análisis de la cultura propia, pautados desde las redes del poder, si bien condicionó en parte los enfoques desarrollados por él, en definitiva no alteraron su capacidad de producción autónoma, la publicada o la anunciada.

En el único trabajo editado en solitario, despliega su condición de dirigente político originario, más que la de etnógrafo recopilador de tradiciones originarias. Allí no se aprecia influencia externa, ni como patrocinador ni como coautoría. En ¡Las Tierras de Arauco! El último cacique, publicado en 1915 en Temuko, además de discursos leídos en reuniones y congresos araucanistas, aparece también el proyecto de Ley presentado en 1926, cuando era diputado Liberal. Allí que plantea la idea que será sólo la propiedad privada la que servirá a la promoción del pueblo mapuche.

En ambos textos se aprecian claramente las influencias ideológicas que el discurso público de la identidad étnica porta en Mañkelef. Este asume en plenitud las ideas liberales que consagran la iniciativa individual por sobre la colectiva; la superación de la pobreza vía la educación, asumiendo a su vez tácitamente una parte de la antinomia civilización/barbarie, pero invirtiendo el significado de este último concepto por el de "atraso". Así lo expresa en un discurso leído en un Congreso Católico Araucanista, realizado en Santiago en diciembre de 1916, durante su gestión como presidente de la Sociedad Caupolicán: 
[...] que si una hectárea le dejasteis, penséis que es pobre y que es ignorante; que ese terrenito debéis dárselo saneado, no entregárselo en común para que forzosamente el tinterillo, el abogado inescrupuloso, el explotador de indios vaya a sembrar entre ellos la discordia para que solos se den el gusto de ser dueños un momento [...], la inferioridad de nuestra raza sólo está en la mente del usurpador, seremos un pueblo atrasado, pero no somos raza inferior, sino desgraciada” (Mañkelef, citado por Foerster \& Montecino 1988: 22).

En Tierras de Arauco, cuando habla del "estado actual de los indios”, anota ideas similares:

"[Los mapuche,] soportando el duro peso de injusticias sin cuento, caminan como tontificados ante tanta ignominia. Muchos se han civilizado, a pesar del Gobierno y la mayoría, arrebatadas sus riquezas, son hoi unos pobres, miserables víctimas del gobierno y la sociedad en que viven [...], ¿Cómo es posible que un gobierno republicano como el de Chile haya procedido así?, ¿por qué y cómo ha conseguido destruir a esta raza fuerte y valerosa que entró a formar parte de la República, no como pueblo conquistado, que jamás lo fue, sino en virtud de solemnes tratados?” (Mañkelef 1915: 8).

Aquí, evidentemente se aprecia la influencia de su paso por la educación formal, y su temprana inserción social y política con círculos vinculados al liberalismo y a cierta elite académica de raigambre positivista. Pero más allá de esto, creemos, también se advierte una base ideológica que proviene desde el interior de la sociedad mapuche pre-chilena. Esta no era una sociedad igualitaria, sino claramente estratificada. Tal estratificación encontraba sus raíces más profundas en el origen de los linajes familiares. Si bien en tiempos independientes, dada la amplitud del territorio autónomo, se daba una especie de movilidad social y territorial que posibilitaba la creación de nuevos linajes mediante el asentamiento en un determinado territorio; las familias que daban origen a este lofche -la unidad básica de la sociedad mapuche-, es decir los trokiñ, tenían derechos preexistentes con respecto a otros linajes llegados a ese territorio después. Mañkelef tenía plena conciencia de aquello, pues su linaje familiar era trokiñche. Por lo demás, en el citado relato familiar que el mismo escribió para el libro de Guevara, aparece un claro ejemplo de las influencias discursivas en función del discurso de la legitimidad, del que él mismo y su linaje se hace parte. Mañkelef traduce el concepto kümekeche, que literalmente significa "gente buena” o "positiva”, por el de "nobleza”; así como el de küme mollfüñ, que correspondería a una "buena” o "positiva sangre” en función de la pertenencia a un trokiñ, por el de "aristocracia”.

En el normalista entonces, se entremezclan y refunden elementos culturales de compuesta raigambre. Su formación como hijo de longko de un territorio no afectado directamente por la guerra de ocupación, no habiendo padecido por tanto ni desplazamientos ni grandes privaciones en su niñez, lo cual le posibilitó su inserción en el sistema educativo de su tiempo. 
Su paso por la educación formal normalista; la validación académica y después política, lugar donde adquirió un protagonismo que sin embargo quedó trunco. Por último, su retirada silente a raíz del conflicto provocado por sus posturas liberales, en relación a la propiedad de las tierras indígenas, nociones que ya en su tiempo chocaron de frente con el masivo y extendido sentido comunitario que ha acompañado a la mayor parte del movimiento mapuche contemporáneo.

\section{Manuel Mañkelef, fulgor y ostracismo del intelectual y político mapuche}

De la vida como de la obra de Manuel Mañkelef, así como de todos los líderes mapuche de su tiempo, poseemos un conocimiento precario en demasía. Salvo lo efectivamente publicado por el autor de los "Comentarios”, sus intervenciones publicadas en la prensa local y sus intervenciones en la Cámara de Diputados, cuando fue parlamentario; las referencias que otros autores o los participantes de alguna asamblea mapuche hicieron de su obra y persona. Menos evidencia aún tenemos de los varios libros “en preparación” que anunció por distintas vías, ya sea a pie de página de sus escritos o en la correspondencia con gente como Lenz. Por referencias, se escuchan algunas noticias de su presumiblemente vasto gabinete, de su archivo y biblioteca personal, la cual suponemos fue nutriendo a medida que aumentaba su prestigio y contactos con intelectuales y académicos chilenos y extranjeros.

Sabemos, eso sí, que la abrupta fuga de la figura de Mañkelef del espacio público mapuche y académico de su tiempo, coincide con su ruptura con la SCDA, organización que ayudó a fundar y presidió en su momento, y por extensión, con la mayoría de los referentes que conformaban para 1926 el movimiento mapuche. Mañkelef, en ese momento, era diputado en ejercicio, habiendo sido electo con apoyo de su organización, pero en un cupo que lo propició su militancia en el Partido Liberal Democrático. La ruptura de Mañkelef con sus correligionarios mapuche tuvo una gran causa; su proyecto de Ley, del que venía hablando desde la publicación de sus Tierras de Arauco (1915). Este, como se sabe, propugnaba la división de las reducciones con títulos de merced en propiedades individuales. Este proyecto fue finalmente aprobado y promulgado como la Ley 4.169 de $1927^{14}$.

El quiebre a raíz de esto, tanto con su propia organización, como con otras como la Federación Araucana de Manuel Aburto Panguilef, fue casi inmediato pues el proyecto suponía contravenir uno de los fundamentos discursivos -la defensa del comunitarismo- levantados por la mayor parte del movimiento mapuche de entonces: "Este nombre [el de Manuel Manquilef] no figura ya en la más prestigiosa institución araucana, cual es la Sociedad Caupolicán”, afirmaba tajante en diciembre de 1926 el entonces presidente de la SCDA, Arturo Huenchullan Medel (ver Nota 12). Aquel fundamento, el del comunitarismo, trascendería en el tiempo hasta la 
promulgación, por la vía de los hechos consumados, de parte de la dictadura pinochetista, del conocido DFL 2568 de 1979, que terminó dividiendo las reducciones que aún se regían por los Títulos de Merced.

El proceso de distanciamiento del preceptor normalista de la organización que ayudó a fundar, resultó ser irreversible y no obstante un par de apariciones en algunas iniciativas posteriores, más bien esporádicas, su rumbo se extravió de las subsiguientes contiendas del movimiento, hasta su muerte acaecida en 1950. De sus actuaciones y sus derroteros en el mundo de la política activa, como el actor clave que fue en los primeros años del movimiento mapuche contemporáneo, así como de su rol como uno de los primeros, sino el primer autor que podemos en propiedad denominar "intelectual mapuche", creemos poder hacer un incipiente ejercicio de extrapolación que pueda eventualmente alimentar actuales reflexiones y debates, tanto hacia el interior del movimiento mapuche, como en su periferia.

Antes que todo, se manifiesta la urgente necesidad, para los actuales investigadores, de indagar mayor cúmulo de antecedentes, en primer lugar, acerca del contexto general y específico donde se origina este movimiento. El contexto del centenario de Chile, en 1910, es un momento de gran reverberación y agitación en el terreno de lo político y social. Ese impulso también alcanza a la producción intelectual y artística. Son años en que una parte de las élites vinculadas a la oligarquía tradicional y otros sectores sociales y políticos emergentes, como cierta burguesía ilustrada, más otros sectores militantes del movimiento social, en lo que se llamó la "cuestión social”, se interrogan y cuestionan acerca del origen y carácter de una nación que recién termina de delimitar sus fronteras y, por lo mismo, no acababa de tener una imagen completa de sí misma.

La ideología nacionalista se constituye entonces en la "fuerza cultural dominante de las primeras décadas del siglo XX” (Subercaseaux 2006). A modo de una argamasa que permitió unificar a los distintos sectores sociales chilenos, fueron las herramientas del arte, la cultura y la ciencia, las que muy eficientemente contribuyeron a insuflar transversalmente dicha ideología. Es en este contexto chilenizante donde se gestan precisamente, no sólo las publicaciones hechas por Mañkelef ${ }^{15}$, sino que ciertos auditorios donde se expresaron los principales oradores del movimiento. Estos circuitos posibilitaron a estos líderes hacer circular sus ideas y propuestas. La principal de éstas, una hábil forma de retruécano conceptual que proporcionó a esos voceros mapuche un eficiente argumento para reforzar el discurso de la legitimación -“somos los primeros chilenos”. El mayor logro de las organizaciones mapuche del periodo, aparte de convertirse en la más transversal de las reivindicaciones del movimiento mapuche contemporáneo, consistió en frenar las usurpaciones territoriales y la violencia hacia las reducciones. Resalta aún más aquella conquista, al contraponerla con el triunfalista ambiente chileno de los años cercanos al primer centenario, cuando la oligarquía toma control de la memoria de la nación, transformando en tema oficial de Estado su propia versión de la historia de Chile. Se 
instauran las efemérides y la galería de héroes nacionales oficiales a ser venerados. Quizás también, producto de ello, se haya asentado conceptualmente en aquel tiempo cierto racismo hacia el pueblo mapuche, plenamente vigente hasta nuestros días.

Es evidente que tanto los primeros liderazgos organizacionales mapuche, así como el surgimiento de cierta incipiente intelectualidad originaria, categoría ocupada hasta ahora casi en exclusiva por Manuel Mañkelef, se generó a contrapelo de instancias que estaban planificadas para producir efectos contrapuestos. Lo cual se puede apreciar tanto en el caso de los preceptores normalistas devenidos en dirigentes étnicos, como en los textos de Mañkelef que, de una parte, fueron instigados por los afanes etnográficos de las investigaciones filológicas de Rodolfo Lenz y, por otra, insertos en iniciativas de exaltación patriótica chilena.

Aun a pesar de todo esto, situándonos desde una perspectiva crítica y de reconstrucción de una historia de las ideas mapuche del siglo XX, podemos en propiedad situar tanto a la fragmentaria figura de Manuel Antonio Neculman, como especialmente a Manuel Mañkelef, como actores inaugurales y claves de un debate de absoluta contingencia dentro del terreno de las relaciones interétnicas mapuche-chilenas. Específicamente, en el delicado y sinuoso espacio del control y circulación del conocimiento mapuche y su ligazón con sujetos y la propia institucionalidad académica.

Contextualmente, hoy quizás sorpresivamente, se dan ciertos elementos en algo cercanos al escenario en que se formaron los primeros contingentes normalistas mapuche de fines del siglo XIX. Lo primero, es que actualmente contamos con algunas generaciones de sujetos que han accedido a la educación superior -vía sistema de becas públicas y/o privadas sustentadas en un criterio de “discriminación positiva” inaugurado hace un par de décadas- y que, dentro de este espacio, están elaborando y reelaborando ahora mismo conocimientos y escrituras donde se reflexiona críticamente sobre distintos aspectos de la situación colonial (ver los trabajos de Zapata, cf. bibliografía). Estos "intelectuales mapuche”, como se les ha denominado, se han insertado y eventualmente validado en forma individual dentro del sistema académico chileno. Es una pequeña elite que no ha constituido un grupo de poder, pero que es reconocible para los interesados y estudiosos del tema. Sin embargo, este sector no es todavía un grupo con poder académico y político autónomo dentro de la academia, al constituir más bien una suma de individualidades, sujeta en la mayor parte de los casos al eventual peso e influencias -lo mismo que Mañkelef-de las relaciones unipersonales elaboradas dentro del sistema.

Principios del siglo XX es seguramente el tiempo del quiebre más profundo que haya padecido la sociedad mapuche. En esa desestructuración, era la lógica de las urgencias la que comandaba las respuestas posibles articuladas por lo nuevos liderazgos. No fue extraño entonces que se fortaleciera el discurso que buscaba la legitimidad retomando una parte de los argumentos nacionalistas chilenos. Bajo este paraguas discursivo, se 
apertrecharon las búsquedas colectivas y sobre todo individuales que buscaron esa legitimidad por el camino del reconocimiento social que proporcionaba la pertenencia a instituciones cargadas de simbolismo, como fueron las numerosas sociedades científicas o histórico-culturales que florecieron por esos años, o la cultivaron a través de lo que hoy denominamos agenciamiento, es decir relaciones unipersonales ventajosas.

La experiencia de construcción del movimiento mapuche desde 1910, ha sido uno de los grandes logros socioculturales mapuche en la etapa post-ocupación. Dicho “éxito” radica precisamente en la capacidad de las organizaciones creadas desde entonces de convertirse en actores políticos colectivos, que con mayor o menor intensidad y eficiencia han logrado interlocutar y negociar parte de las demandas mapuche contemporáneas. Por otro lado, la relación entre la militancia y el trabajo intelectual encuentra en la figura de Manuel Mañkelef una síntesis de las variables que, tanto en su época como hoy en día, componen un complejo y no resuelto vínculo. En cuanto miembro fundador y luego presidente de la SCDA, el preceptor desarrolló una activa labor dirigencial que empezó a agrietarse casi simultáneamente al desarrollar sus inquietudes escriturales y sus relaciones con la academia chilena.

¿Cuál podría ser el encuadre y los límites entre la militancia étnica y la autonomía del trabajo intelectual surgido y sustentado en la militancia política? Es una pregunta que en el caso de Mañkelef se respondió en el enfrentamiento y posterior ostracismo del antiguo líder. Es probable que la acendrada imagen de sí mismo que el preceptor había desarrollado, luego de ver publicada parte de su obra en los Anales de la Universidad de Chile y siendo posteriormente elegido diputado, no fuera compatible con una militancia que se conflictuó severamente. Es que Mañkelef elaboró su trabajo intelectual sin generar espíritu de colectividad de pensamiento al interior de su organización y fue seguramente debido a esto que la más polémica de sus propuestas ${ }^{16}$, como fue la división de las reducciones emanadas de los Títulos de Merced, fuera masivamente rechazada por el resto de la dirigencia $y$, suponemos, también en la militancia.

En términos estructurales, puede que exista algún nivel de cercanía entre la situación actual con el contexto del centenario que vivieron nuestros protagonistas. Más que por un simple efecto derivado de la efeméride chilena, por la persistencia del modelo de Estado nacional monoétnico terminado de construir tan eficientemente por esos años, a, que ve en el empoderamiento político mapuche condensado en rótulo “conflicto mapuche” una severa amenaza a su persistencia. La presente necesidad -que no es masiva aun- de reforma estructural a ese modelo, vía la reforma política al marco constitucional propugnada por algunos sectores, va desde un -a estas alturas inocuo- "reconocimiento constitucional” de los pueblos indígenas, hasta un eventual Estado plurinacional, pasando por otras medidas intermedias. 


\section{A modo de conclusión}

Hoy es claro, existe un cierto interés por lo mapuche en ciertos sectores académicos y también en círculos solidarios, que ya no se enfoca sólo en la pretensión del registro museográfico de costumbres y elementos culturales a punto de desaparecer como antes. Aparte de esa línea de la investigación etnográfica neutra, que siempre ha existido, se indaga hoy, entre otras temáticas, en los nuevos actores, discursos y prácticas culturales. Los intelectuales indígenas, sus reflexiones y sobre todo sus textos, también son hoy materia de análisis. Pese a todos los ejercicios de extrapolación que puedan hacerse, lo seguro es que aquellas primeras generaciones normalistas mapuche, y el propio Mañkelef en particular, no dispusieron de la batería de herramientas analítico-conceptuales actuales. Eso, además de la posibilidad de generación de redes, virtuales o físicas, de intercambio de conocimientos y experiencias con otros sujetos y contextos sociopolíticos similares. Los normalistas devenidos en líderes e intelectuales mapuche se desenvolvieron e hicieron su labor en un territorio en el que todos los argumentos y discursos estaban en contra.

Todo ejercicio de extrapolación entre dos contextos tan lejanos sólo puede ser provechoso si se articula en torno a preguntas que crucen tangencialmente los ejes del debate. En lo que concierne al trabajo intelectual indígena en situación colonial, pensamos que se dan interrogantes que son permanentes entre uno y otro escenario. Una de ellas es el cuestionamiento sobre las opciones y oportunidades reales de generación de pensamiento autónomo cuando no se tiene poder efectivo. Preguntarse también, vistas las sutilezas de los mecanismos de poder actuales, sobre los peligros subyacentes a la producción de conocimientos, puestos a circular en un ambiente donde los mecanismos de poder políticos y académicos, en gran medida, se mantienen incólumes. En el actual escenario, continúa siendo evidente el tenue límite fluctuante entre la posibilidad de generar pensamiento que aporte efectivamente a un proyecto de liberación nacional mapuche, y los riesgos implícitos que mucha de la energía depositada en producciones intelectuales propias, ya sea en el campo de lo sociocultural e incluso en lo político, se diluya en el insondable territorio de unas estériles clasificaciones taxonómicas. Cuando no, que esas producciones acaben siendo diseccionadas etnográficamente, instrumentos de análisis hoy muchísimo más sutil y elaborado que hace un siglo atrás.

Se hace necesario analizar críticamente un contexto y unos protagonistas que son fundamentales para la historia mapuche contemporánea, personajes y circunstancias aun poco estudiadas o, sintomáticamente, estudiadas “a medias”. Conocer más, por ejemplo, de aquellas primeras generaciones de líderes organizacionales mapuche, en particular de aquellos territorios ensombrecidos por el olvido y la mala memoria. Al respecto, conocer más de la figura y obras de Manuel Mañkelef, implica hoy un gesto cargado de urgencias. Más todavía, cuando es la propia situación política de la Araucanía interétnica, y del país actual, lo que da sentido y razón a estos probables análisis. 
Mucho ha cambiado la sociedad mapuche -en lo formal e informaldesde aquellos años de los preceptores-dirigentes y de las primeras experiencias organizacionales. Poco y nada han cambiado, sin embargo, las estructuras del poder político estatal chileno, en sus actores, intereses en juego y en sus particulares relatos sobre el pueblo mapuche. Aquella mirada fragmentaria e incompleta, tan bien representada por la topografía reduccional y en el fracaso a priori del proyecto integrador encerrado en el canon "civilizados a medias", sigue campeando en la arbitraria división entre mapuche "buenos" y "malos"; en las políticas públicas no implementadas, o implementadas "a medias"; en los diálogos ausentes; en los asesinatos sin culpables; en el miedo vestido de racismo hacia esa esquina que no calza dentro del desatado proyecto neoliberal chileno. 


\section{Notas}

${ }^{1}$ La traducción textual del concepto es "gente de buena sangre". Alegóricamente, refiere a una idea de prestigio social de un linaje mapuche, vinculándose allí elementos como la antigüedad, familia numerosa y bienes acumulados en la guerra.

${ }^{2}$ Longko -literalmente “cabeza”- es el jefe de un lof o núcleo social básico de la sociedad mapuche tradicional.

${ }^{3}$ El gabinete etnológico guevariano de Temuco sintetiza muy adecuadamente una política de división del trabajo y los roles asociados del trabajo etnográfico clásico, asentándose en aquel recinto la figura del autor y del informante nativo. El primero, frecuentemente encubierto en las autorías, era sin embargo un sujeto clave para cualquier investigador, pues era capaz de desentrañar los secretos culturales sintetizados en una lengua, que pese a ser de "salvajes", contenían todas las complejidades de la diferencia. Es en semejante afán que se entrecruzan en el camino dos lógicas completamente opuestas, como lo ha planteado Pavez (2003), para la obra guevariana. Una, la del investigador que intenta retratar a las "últimas familias i costumbres...", y la otra, de sus ayudantes liceanos y posteriores normalistas, que por virtud de la misma historia que les tocó vivir, derivaron en dirigentes étnicos que vieron en la escritura de la memoria mapuche, y en el acceso masivo a la educación formal, una posibilidad mínima de redención ante la asonada estatal chilena. El propio Mañkelef, con un dejo de ironía, que al parecer le era característica, recoge esta categoría en la dedicatoria de sus Comentarios, la faz social donde, en la sección "dedicatoria”, se presenta como uno de "los últimos vástagos de la raza que con gran tenacidad supo defender durante tres siglos i medio de lucha la integridad de su suelo" (Manquilef [Mañkelef] 1911: 12).

${ }^{4}$ Ejemplos preclaros de aquella condición -esto es, hijos de longko, normalistas, dirigentes e intelectuales- son Manuel Antonio Neculman, quien estuvo a cargo de la primera escuela pública que hubo en Temuko (ver Nota 5), y Manuel Mañkelef, quien fue alumno de Neculman justamente en esa escuela elemental, dos personajes fundamentales para la historia mapuche contemporánea. Provenientes de sectores similares dentro de la sociedad mapuche y formados a su vez por la institución creada por Sarmiento, tanto en su sede central de Santiago como en la de Chillán, ambos ejercieron su profesión y se convirtieron luego en líderes sucesivos de la primera organización mapuche contemporánea, la Sociedad Caupolicán Defensora de la Araucanía -en adelante SCDA. Neculman de hecho presidió la SCDA desde su fundación en 1910, hasta 1916, año en que asume el cargo el propio Mañkelef.

${ }^{5}$ Pese a que el nombre oficial de esta ciudad es "Temuco", se usará en este trabajo la ortografía “Temuko", que fonéticamente es más acorde con la pronunciación del idioma mapuche o mapuzungun.

${ }^{6}$ Foroweche es un gentilicio que refiere pertenencia al territorio de Forowe castellanizado como Boroa-: "forowe” indica el lugar, mientras el sufijo "che” refiere a las personas que lo pueblan; o sea "gente de Forowe".

${ }^{7}$ Lorenzo Koliman fue el primer ayudante trascriptor de Guevara. Raptado de su familia por el propio Saavedra, no alcanza a recibirse de preceptor normalista, pues marcha a combatir en la Guerra del Pacífico. Trabaja luego como traductor en el Juzgado de Angol. Finalmente, termina trabajando como profesor particular en reduc- 
ciones mapuche cercanas a Temuko: "lo que hemos conseguido con la civilización que dicen nos han dado es vivir apretados como el trigo en un costal”, afirma en la trascripción de la historia de su linaje, escrita por él para las Historias de Familias de Guevara (2002 [1912]: 44).

${ }^{8}$ Cornelio Saavedra envía carta al ministro de Guerra, en la que le anuncia la convocatoria al Parlamento de Hipinco, en las cercanías de Puren, convocado para el 22 de noviembre de 1869, al cual estaban convocadas las jefaturas de Maquehua, Boroa, Imperial, Allipen, Panguipulli, Villarrica, entre otras. En este, se esperaba obtener la fidelidad del mayor número de longko ante el temor que suscitaba a los militares la actitud rebelde de Külapang por un lado, y la presencia del auto-proclamado Rey de la Araucanía y la Patagonia, Orelie Antoine de Tounens, por el otro. Dice Saavedra, en un párrafo de la carta: "Inspirándome poca fé las promesas de sumisión que puedan hacerme los indios, exigiré a los Caciques que soliciten la amistad del gobierno, la entrega de uno de sus hijos como prenda de fidelidad, el que será educado por cuenta de la nación. La negativa o excusa que encuentre para aceptar este pedido, me dará a conocer el grado de compromiso que los ligue con los rebeldes [...]” (en Navarro L. 2008: 182).

${ }^{9}$ Extracto del artículo “Conquista de Arauco”, publicado en el diario El Ferrocarril, 2027 mayo 1859, Santiago de Chile.

${ }^{10}$ Filólogo alemán llegado a Chile en 1889, Rodolfo Lenz fue el autor de la primera y precursora obra de recopilación y análisis del idioma mapuche, Estudios Araucanos (1895-1897), y posterior revisor y editor de prácticamente todas las obras araucanistas consideradas clásicas de principios del siglo XX.

11 "Hasta en los mapuches que han cambiado de hábitos i traje i que viven en pueblos, se conserva el olor desagradable i característico de las razas inferiores”, afirma Guevara (1908: 154) en una de sus obras, quizás pensando en su ayudante principal.

${ }^{12}$ Ver al respecto el documento "Comité Ejecutivo de la Araucanía de Chile. Actas del Congreso Araucano, Collico, Ercilla, 24-27 de diciembre de 1926”, publicado en los Anales de Desclasificación, Vol. 1 (2005: 75-77).

${ }^{13}$ Las doce cartas enviadas por Manuel Mañkelef a Rodolfo Lenz, que se conservan en el Archivo Lenz del Instituto Pedagógico, abarcan desde marzo de 1912 a noviembre de 1915. Es el período en que el preceptor está agenciando la publicación de sus Comentarios, evidentemente según las necesidades prefijadas por el filólogo alemán. Mañkelef aquí pide consejo (“¿cree Ud., que se puede presentar mi literatura al Congreso Científico de Temuko?”, el 22/10/1912), averigua sobre sus textos (“le agradecería me dijera lo que se ha acordado con respecto de mi Jimnasia, porque hace ya un año que está allá”, el 4/6/1913), hace indicaciones de edición no atendidas por Lenz ("le ruego que después de jimnasia nacional le ponga contribución al estudio de la historia patria”, el 18/7/1913), anuncia obras y ponencias ("quiero adherirme al congreso de la paz i deseo presentar un trabajo sobre los proverbios araucanos”, el 7/8/1914), entre otras materias. Pero, por sobre todo, queda en evidencia en estas cartas el profundo quiebre que ya se había producido entre Mañkelef y Guevara ("Mi amigo don T.G está enojado como un diablo por la cuestión cátedra. Dice que soi un ignorante, un flojo i otros calificativos que tienden a desprestigiarme”, el 13/3/1913; "En este liceo todo el mundo está feliz con la llegada del señor Letelier; todos han encontrado al amigo en 
vez de la farsa y la terquedad del seudo-sicólogo Guevara”, el 4/6/1913; “¿qué me dice de T.G.? [...] el papel que desempeña para con la raza araucana i la necesidad de expulsarlo de la Sociedad Caupolicán”, el 28/4/1914). Agradezco a Jorge Pavez haberme facilitado copia digital de estas cartas.

${ }^{14}$ El artículo $1^{\circ}$ de esta ley decía textual: "Un tribunal especial con asiento en la ciudad de Temuko, procederá a la división de las comunidades indígenas que tengan título de merced" (Anales de Desclasificación, vol.1, $\mathrm{n}^{\circ}$ 1, 2005: 75). El sentimiento antiradicación y anti-propiedad colectiva, como solución a la postración mapuche, se había afincado en el ideario de Mañkelef mucho antes de esta ley, previo incluso a ser proclamado como presidente de SCDA. Así lo argumentó largamente en su Tierras de Arauco (1915), donde afirma entre otras cosas que: “[...] con la radicación no se ha hecho más que dividir la Araucanía en tantas araucanías chicas como comunidades donde vive el espíritu araucano, pero no ya indomable como antes, sino corrompido en parte por los vicios que le inyectó el gobierno civilizador” (Mañkelef 1915: 10).

${ }^{15}$ Afirma Lenz en el Prefacio de la Faz social: "pedí al señor Manquilef, que se había ofrecido como miembro a la Sociedad de Folklore Chileno, que nos diera una breve autobiografia. La presento a los lectores de esta Revista a continuación”. Más adelante, en esta misma publicación, un jurado de tres miembros de aquella Sociedad, en la sección "Orijen de este trabajo", afirma: "Habiéndose organizado un certamen literario-científico para conmemorar nuestra emancipación política, se procedió a nombrar un jurado [...] poniendo como tercero "Un trabajo que desarrolle una faz de la vida araucana, [el que] resultó pertenecer a don Manuel Manquilef” (1911: 3-4; 9-10). No olvidemos que el propio Mañkelef propone a Lenz, en carta fechada el 18/7/1913: "Nota. Le ruego que después de Jimnasia Nacional, le ponga, contribución al estudio de la $\mathrm{H}^{\mathrm{a}}$ Patria”. Se refiere obviamente a la historia patria de Chile.

${ }^{16} \mathrm{La}$ confrontación entre propiedad comunitaria y propiedad privada fue resuelta temprana y persistentemente por el movimiento mapuche a favor de la primera. El argumento central de esa defensa fue el temor a perder las escasas tierras conservadas en los Títulos de Merced y su eventual ampliación. De haber generado Mañkelef un sector opinante a favor de sus planteamientos, este debate, que históricamente ha circulado en el ámbito de la informalidad mapuche, habría seguramente desarrollado otras aristas. 


\section{Bibliografía}

Guevara, Tomás (1908), Psicolojia del Pueblo Araucano, Imprenta Cervantes, Santiago de Chile.

Idem (1912), Últimas familias i costumbres araucanas, Imprenta, litografía i encuadernación Barcelona, Santiago de Chile.

Guevara, Tomás \& Manuel Mañkelef (2002), Kiñe mufü trokiñche ñi piel: Historias de familias / Siglo XIX, CEDM Liwen / CoLibris Ediciones, Temuko / Santiago.

Foerster, Rolf \& Sonia Montecino (1988), Organizaciones, Líderes y Contiendas Mapuches (1900-1970), Centro Estudios de la Mujer, Santiago de Chile.

Le Bonniec, Fabien (2011), "Mitos y realidades acerca de la figura de la intelectualidad mapuche en la edad del multiculturalismo neoliberal chileno”, en Cuadernos Interculturales, Año 9, № 17, Universidad de Valparaíso, Viña del Mar, pp. 53-71.

Lenz, Rodolfo (1895-1897), Estudios Araucanos, Imprenta Cervantes, Santiago de Chile.

Mallon, Florencia (2010), “La ‘Doble Columna’ y la 'Doble Conciencia’ en la Obra de Manuel Manquilef”, en Revista de Antropología, N²1, Universidad de Chile, Santiago, pp. 59-80.

Manquilef [Mañkelef], Manuel (1911), “Comentarios del Pueblo Araucano: La Faz social”, en Anales de la Universidad de Chile, Vol. CXXVIII, Santiago de Chile, 1er semestre, pp. 395-450.

-Idem (1914), “Comentarios del Pueblo Araucano, II: La gimnasia Nacional (Juegos, Ejercicios y Bailes)”, en Anales de la Universidad de Chile, Vol. CXXXI, Santiago de Chile, febrero, pp.257-301, 801-883.

Idem (1915), ¡Las Tierras de Arauco! El Último Cacique, Imprenta y Encuadernación “Modernista”, Temuko.

Matus Zapata, Leotardo (1915), “Instrucciones para el estudio de la antropolojía araucana”, en Boletín del Museo Nacional de Chile, Vol. 8, pp. 21-33.

Idem (1920), “Juegos y ejercicios físicos de los antiguos araucanos”, en Boletín del Museo Nacional de Chile, Vol. 11, pp. 162-197.

Menard, André (2006), “Emergencia de la tercera columna en el texto: 'La faz social', fragmento de los Comentarios del pueblo araucano de Manuel Mañkelef”, en Anales de Desclasificación, Vol. 1, N² 2, pp. 927-973. 
Moesbach, Ernesto Wilhelm de (1930), Vida y costumbres de los araucanos en la segunda mitad del siglo XIX, Imprenta Cervantes, Santiago de Chile.

Munizaga, Carlos (1960), Vida de un Araucano. El estudiante mapuche L.A. en Santiago de Chile, en 1959, Editorial Universitaria, Universidad de Chile.

Navarro, Leandro (2008), Crónica militar de la conquista y pacificación de la Araucanía, Pehuén Editores, Santiago de Chile.

Núñez Prieto, Iván (2010), "Las escuelas normales: una historia de fortalezas y debilidades. 1842-1973”, en Revista Docencia, № 40, mayo, Colegio de Profesores, Santiago de Chile, pp. 32-39.

Pavez, Jorge (2003), “Mapuche ñi nütram chillkatun / Escribir la historia mapuche, estudio posliminar de Kiñe mufü trokiñche ñi piel, historias de familias, siglo XIX”, en Revista de Historia Indígena, $\mathrm{N}^{\circ}$ 7, Universidad de Chile, Santiago de Chile, pp. 7-53.

Préndez, Pedro Nolasco (1884), Una escursion de verano de Angol a Villarrica y Valdivia en los primeros meses de 1883, Imprenta "La Patria”, Valparaíso.

Sarmiento, Domingo Faustino (1845), Civilización y barbarie: vida de Juan Facundo Quiroga y aspecto físico y costumbres y hábitos de la República Argentina, Imprenta del Progreso, Santiago de Chile.

Subercaseaux, Bernardo (2006), Historia de las ideas y de la cultura en Chile - Tomo IV, Nacionalismo y Cultura, Editorial Universitaria, Santiago de Chile.

Zapata Silva, Claudia (2005), "Identidad y sujeto en la escritura de los intelectuales mapuches de Chile (1993-2003)”, Claroscuro, Año IV, Nº 4, Universidad Nacional de Rosario, pp. 51-76.

Idem (2005b), “Michel Foucault, los intelectuales y la representación. A propósito de los intelectuales indígenas”, Cyber Humanitatis, $\mathrm{N}^{0} 35$, Universidad de Chile, en línea: http://web.uchile.cl/vignette/cyberhumanitatis/ CDA/texto_sub_simple2/0,1257,PRID\%253D16159\%2526SCID \%253D16162\%2526ISID\%253D576,00.html.

Idem (2006a), “Identidad, nación y territorio en la escritura de los intelectuales mapuches”, Revista Mexicana de Sociología, Año 68, № 3, Universidad Nacional Autónoma de México, México D.F, pp. 467-509.

Idem (2006b), “Los intelectuales indígenas y la representación. Una aproximación a la escritura de José Ancan Jara y Silvia Rivera Cusicanqui”, Revista de Historia Indígena, N 9, Universidad de Chile, Santiago, pp. 51-84. 
Polis, Revista Latinoamericana, Volumen 13, $N^{\circ}$ 38, 2014

Idem (comp.) (2007a), Intelectuales indígenas piensan América Latina, UASB / CECLA / Abya Yala, Quito.

Recibido: 15.05.2014

Aceptado: 15.07.2014 